\title{
The Impact of Modifiable Lifestyle Factors on the Prognosis of Breast Cancer Survivors
}

\author{
Wolfgang Janni \\ Frauenklinik, Klinikum der Heinrich-Heine-Universität Düsseldorf, Germany
}

Modifiable lifestyle factors have been described to be of significant impact on the prognosis of breast cancer patients. Maintaining a normal body mass index and increasing physical activity has been confirmed to have favorable impact on prognosis in multiple trials, and nutrition experts recommend the adherence to general nutrition guidelines, which take into account the complexity of dietary values. Also smoking and drinking habits may have an influence on prognosis and risk of recurrence: In a recent cohort analysis Li et al. [1] utilized a population-based nested case-control study design, which enrolled 365 patients diagnosed with an estrogen receptorpositive $(\mathrm{ER}+)$ first primary invasive breast cancer and a second primary contralateral invasive breast cancer, and 726 matched controls diagnosed with only an ER+ first primary invasive breast cancer. Obesity, alcohol use, and smoking data were taken from medical record reviews and participant interviews. Using conditional logistic regression, they evaluated associations between these three exposures and the risk for second primary contralateral breast cancer. Obesity, consumption of 7 or more alcoholic beverages per week, and current smoking were all positively related to risk of contralateral breast cancer (odds ratio (OR), 1.4; 95\% CI, 1.0 to 2.1; OR, $1.9 ; 95 \%$ CI, 1.1 to 3.2 ; and OR, 2.2; $95 \%$ CI, 1.2 to 4.0 , respectively). Compared with women who consumed fewer than 7 alcoholic beverages per week and who were never or former smokers, women who consumed 7 or more drinks per week and were current smokers had a 7.2-fold (95\% CI, 1.9 to 26.5) elevated risk of contralateral breast cancer. This study adds to the already available literature and suggests that obesity, smoking, and alcohol consumption influence contralateral breast cancer and recurrence risk.

In Germany, the SUCCESS C trial [2], prospectively randomizing patients to either intensive lifestyle counseling or minimal counseling with a target number of more than 3,500 patients will not only be the largest trial on this topic worldwide, but will also provide valuable prospective data on the relevance of lifestyle for breast cancer survivors. Once again, Germany proves to be the home of innovative and practice changing medical research.

This issue of BREAST CARE will focus on different aspects of modifiable lifestyle factors from different experts' perspectives [2-5]. In summary, it is quite obvious that changing patients' lifestyle might influence the prognosis in some patients in a magnitude comparable to systemic treatment. On the other hand, there may be patients who find it much harder to change habits and personal lifestyle than to tolerate the adverse effects of systemic treatment. This issue of BREAST CARE may contribute to our awareness of the influence of lifestyle factors on the course of disease and help us to accept the challenge of discussing these aspects with our patients and offer them our counseling. It would be well worth it!

'Curious things, habits. People themselves never knew they had them.'

Agatha Christie

\section{References}

1 Li CI, Daling JR, Porter PL, Tang MT, Malone KE. J Clin Oncol. 2009 Nov 10;27(32):5312-8. Relationship between potentially modifiable lifestyle factors and risk of second primary contralateral breast cancer among women diagnosed with estrogen receptor-positive invasive breast cancer.
Rack B, Andergassen U, Neugebauer J, Salmen J, Hepp P, Sommer H, Lichtenegger W, Friese K, Beckmann MW, Hauner D, Hauner H, Janni W: The German SUCCESS C study - the first European lifestyle study on breast cancer. Breast Care 2010;5:395-400.

3 Hauner H, Hauner D: The impact of nutrition on the development and prognosis of breast cancer. Breast Care 2010;5:377-381.
Muenstedt K, El-Safadi S: Nutritive supplements - help or harm for breast cancer patients? Breast Care 2010;5:383-387.

5 Graf C, Wessely N: Physical activity in the prevention and therapy of breast cancer. Breast Care 2010;5:389-394.

\section{KARGER}

Fax +497614520714

Information@Karger.de

www.karger.com (c) 2010 S. Karger GmbH, Freiburg

Accessible online at:

www.karger.com/brc
Univ.-Prof. Dr. med. Wolfgang Janni

Direktor der Frauenklinik

Klinikum der Heinrich-Heine-Universität Düsseldorf

Moorenstraße 5, 40225 Düsseldorf, Germany

Tel. +49 211 81-17501, Fax -18483

Wolfgang.Janni@med.uni-duesseldorf.de 